\title{
I-Kappa-B Kinase
}

National Cancer Institute

\section{Source}

National Cancer Institute. I-Kappa-B Kinase. NCI Thesaurus. Code C104199.

An enzyme complex that is involved in serine/threonine phosphorylation, inflammation and the regulation of the nuclear factor kappa-light-chain-enhancer of activated B cells protein complex. I-kappa-B kinase is comprised of three proteins, inhibitor of nuclear factor kappa-B kinase subunit alpha, beta and gamma. 